\title{
To Compare the Microleakage Among Experimental Adhesives Contain- ing Nanoclay Fillers after the Storages of 24 Hours and 6 Months
}

\author{
Seyed Mostafa Mousavinasab ${ }^{*, 1}$, Mohammad Atai $^{2}$ and Bagher Alavi ${ }^{3}$ \\ ${ }^{1}$ Isfahan University of Medical Sciences, Dental School, Department of Operative Dentistry and Torabinejad Research \\ Centre, Isfahan, Iran \\ ${ }^{2}$ Iran Polymer and Petrochemical Institute (IPPI), Tehran, Iran \\ ${ }^{3}$ Operative Dentistry Department, Dental School, Isfahan University of Medical Sciences, Isfahan, Iran
}

\begin{abstract}
:
Objectives: To compare the microleakage among experimental adhesives containing nanoclay fillers after the storages of 24 hours and 6 months.

Materials and Methods: Class V cavities were prepared on extracted human molars with the occlusal margins located in enamel and the cervical margins in cementum. Phosphoric acid was applied to the enamel and dentin margins.Subsequently, the cavities were treated using four groups of experimental adhesive systems and restored with a resin composite. Adper Single Bond ${ }^{\circledR}$ was used as control group. After 24- hour and 6- month storages, the samples were subjected to thermocycling shocks and then immersed in silver nitrate as well as developer solution and finally evaluated for leakage. The data were analyzed using SPSS software.

Results: Based on Kruskal -Wallis test, significant differences were found between groups regarding microleakage. The Mann- Whitney test showed that Leakage was significantly lower in Adper Single Bond® compared to the other groups in dentinal margins after 24 hours and 6 months and in enamel margins after 6 months. The Wilcoxon Signed Ranks test showed that the enamel leakage in experimental adhesives was significantly lower than dentinal leakage after 24 hours as well as enamel leakage in Adper Single Bond and adhesive with 0.5\% PMAA-g-nanoclay was significantly lower than dentinal margins after storage period of 6 months.
\end{abstract}

Conclusion: All the experimental adhesives were effective in reducing enamel leakage after 24 hours, but were not effective in reducing dentinal leakage after 24 hours as well as in enamel and dentinal leakage after a 6-month storage. No improvement was observed in the microleakage in dentin in both short ( $24 \mathrm{hrs})$ and long times (6 months).

The high microleakage in the adhesives is probably attributed to the high concentration of HEMA in the recipe of the bonding agent.

Key Word: Dentin bonding, microleakage, nanoclay, nanoparticle containing adhesives.

\section{INTRODUCTION}

Full depth penetration of resin to demineralized area of dentin is necessary for maximum bond strength [1]. Desired thickness of the adhesive resin layer is estimated to be about 100 microns [2].

Adhesives containing enough thickness of layer and filler can act as a stress liberator and compensate for polymerization shrinkage stresses [3,4] which leads to increasing the bond strength and reducing the microleakage [5]. Bond strength is reduced after water storage for several months [68].

Adhesion to enamel compared to dentin is more stable and reliable. However, new adhesives have shown better

*Address correspondence to this author at the Isfahan University of Medical Sciences, Iran; Tel:0098 311 7922849; Fax: 0098311 6687080; E-mail: s_mousavinasab@dnt.mui.ac.ir, Musavinasab37@yahoo.com results $[9,10]$, Today, keeping marginal seal and durability in long-term are regarded as clinical concerns [11].

Adding filler to the adhesives usually improves mechanical properties of the polymerized adhesive layer $[12,13]$ proprovides an elastic shock absorbing layer and compensating for composite resin polymerization shrinkage $[11,12]$, The properties of the adhesives are affected by many factors, including shape size and surface properties of the fillers as well as continuous phase properties and adhesive systems solvent $[12,14]$.

Because of the variety in combination and adhesive matrix formulation of commercially available filled adhesives, it's not clear whether adding filler will increase bond strength or not [15]. Filler size usually affects the properties of polymer base materials $[16,17]$.

Montmorillonite (MMT) is one of the available forms of nano-clay and it has been shown that it could increase greatly the mechanical properties of polymers [18]. 
Table 1. Materials Used in this Study

\begin{tabular}{|c|c|c|}
\hline Matrials & Description & Composition \\
\hline $\begin{array}{l}\text { Scotchbond etchant gel } \\
\text { (3M ESPE, St. Paul, MN, USA) }\end{array}$ & Etching agent & $\begin{array}{l}\text { Water } \\
\text { Phosphoric acid, synthetic amorphous silica }\end{array}$ \\
\hline $\begin{array}{l}\text { Adper Single Bond } \\
\text { (3M ESPE, St. Paul, MN, USA) }\end{array}$ & Primer-adhesive & $\begin{array}{l}\text { Ethyl alcohol } \\
\text { Bisphenol A,diglycidyl ether dimethacrylate } \\
\text { 2-hydroxyethyl methacrylate } \\
\text { Glycerol 1,3-dimethacrylate } \\
\text { Copolymer of acrylic and itaconic acid } \\
\text { Diurethane dimethacrylate, water }\end{array}$ \\
\hline Experimental adhesive & Primer-adhesive & $\begin{array}{l}\text { Ethyl alcohol (39 wt.\%) } \\
\text { 2,2'-bis-[4-(methacryloxypropoxy)-phenyl]-propane (Bis-GMA) (14 wt. \%) } \\
\text { Urethane dimethacrylate (UDMA) (12 wt. } \%) \\
\text { 2-hydroxyethyl methacrylate (HEMA) (26 wt.\%) } \\
\text { 2-ethyl-2-(hydroxymethyl)1,3-propandiol-trimatacrylate (TMPTMA) (8 wt.\%) } \\
\text { Camphorquinone (0.5 wt.\%) } \\
\text { N-N'-dimethyl aminoethyl methacrylate (DMAEMA) (0.5 wt. \%) }\end{array}$ \\
\hline $\begin{array}{l}\text { Filtek Z250 } \\
\text { (3M ESPE, St. Paul, MN, USA) }\end{array}$ & Light cure composite & $\begin{array}{l}\text { Silane treated ceramic } \\
\text { Bisphenol A polyethylene glycol diether dimathacrylate } \\
\text { Diurethane dimethacrylate } \\
\text { Bisphenol A diglycidyl ether dimethacrylate } \\
\text { Triethylene glycol dimethacrylate, water }\end{array}$ \\
\hline
\end{tabular}

Adhesives containing modified nanoparticles have higher mechanical and microshear bond strength at $0.5 \%$ wt nanoclay content [19]. Adding 10\% nano-filler and using an organically modified clay could increase the cohesive strength of adhesives [20] and potential of GIs as posterior filling materials [21]. The effect of 12-nm hydrophilic fumed silica on the mechanical properties and the microtensile bond strength (MTBS) of an ethanol-based one-bottle dentin adhesive was studied by kim. Adding $0.5 \mathrm{wt} \%$ nanofillers showed the best effect [15]. Sadek assessed the effect of 24hour and 3-month storages on microleakage. The effect of bonding material on microleakage was significant but storage had no effect on microleakage [22]. On the contrary, storage was effective on shear bond strength but it did not influence the microleakage of the cavities in another study [23].

Studies taken place by Crim indicated that in some of the tested bonding systems, storage period was effective on microleakage [24, 25].

Therefore, the purpose of this study was to compare the microleakage between experimental adhesives containing nanoclay fillers after a 24-hour and a 6-month storages.

\section{MATERIALS AND METHODS}

\section{Synthesis of Modified Nano-Particles}

Cloisite $\mathrm{Na}^{+}$(montmorillonite, typical dry particle size $90 \%$ less than $13 \mu \mathrm{m}$, Cloisite Na, Southern Clay, USA) was used to prepare modified nano-clay in the present study. This type of nano-clay is hydrophilic without any modification. Firstly, clay particles were spread in water to separate the platelets. Poly(acrylic acid) (PMAA) and poly(methacrylic acid) (PAA) were grafted onto the pristine Na-MMT nanoclay (Cloisite $\mathrm{Na}^{+}$) through the free radical polymerization of acrylic acid and methacrylic acid monomers in an aqueous media in the presence of ammonium persulfate as initiator. A reactive surfactant (AMPS) was also used in the reaction to provide active sites on the surface of the nanoclay particles. The grafting polymerization reaction was carried out at $70{ }^{\circ} \mathrm{C}[19]$.

After drying and milling, various quantities of the prepared nano-clay were added to the test sample solution.

\section{Preparation of the Adhesives}

$0.5 \%$ of nano-clay modified with methacrylic acid and $0.2 \%$ of nano-clay modified with acrylic acid and $0.5 \%$ of unmodified nano-clay separately were added to the basebonding system. An experimental bonding system with no added nano-clay filler also was used. The composition of the base adhesive is shown in the Table 1).

\section{Preparation of the Teeth}

Two series, each including of 55 healthy permanent molars without decay were collected during 3 months and stored in $0.5 \%$ chloramine $\mathrm{T}$ solution at room temperature.

A standard class $\mathrm{V}$ cavity with $3 \mathrm{~mm}$ mesiodistal width, 3 $\mathrm{mm}$ height and $2 \mathrm{~mm}$ depth was cut on the buccal surface of each tooth using diamond bur(050406 Germany, Lot: D\&Z) 
Table 2. Degree of Leakage after 24 Hours Storage

\begin{tabular}{|c|c|c|c|}
\hline Adhesive & $\begin{array}{c}\text { Mean Leakage in Dentin } \\
\text { (SD) }\end{array}$ & $\begin{array}{c}\text { Mean Leakage in } \\
\text { Enamel (SD) }\end{array}$ & Degree of Conversion (\%) \\
\hline \hline Un- filled & $3.45(1.29)$ & $0.73(0.64)$ & $27.6(4.1)$ \\
\hline $0.5 \%$ clay & $2.73(1.55)$ & $0.82(0.75)$ & $20.4(1.8)$ \\
\hline $0.5 \%$ PMAA-g-clay & $3.73(1.90)$ & $0.45(0.63)$ & $25.4(3.0)$ \\
\hline $0.2 \%$ PAA-g-clay & $3.45(1.21)$ & $0.45(0.68)$ & $0.55(0.68)$ \\
\hline Single Bond & $0.55(1.52)$ & & \\
\hline
\end{tabular}

SD:Standard Deviation

PMAA-g-clay: poly(methacrylic acid) grafted clay

PAA-g-clay: poly(acrylic acid) grafted clay

under constant water spray so that incisal margin was located $2 \mathrm{~mm}$ above the CEJ and gingival margin $1 \mathrm{~mm}$ below the CEJ. Each new bur was used for five cavity preparations. The prepared samples were randomly divided into two groups including five subgroups, each containing eleven samples.In the first group all the cavities were total etched using 35\% phosphoric acid gel (3M ESPE.St Paul,MN.USA) for 15 seconds and then rinsed for 10 seconds and finally blot dried. The experimental bonding systems were applied in one layer using microbrushes and thinned and after 30 seconds (to ensure solvent evaporation) light cured (Blue phase, Ivoclarvivadent, schoan, Liechtenstein, $550 \mathrm{~mW} / \mathrm{cm}^{2}$ ) using continuous checked mode by radiometer (Demetron/kerr USA) for 20 seconds. plied.

Subgroup 1: experimental adhesive with no filler was ap-

Subgroup 2: test adhesive filled with the unmodified nano-clay was applied.

Subgroup 3: experimental adhesive filled with $0.5 \%$ nano-clay modified with metacrylic acid was applied.

Subgroup 4: experimental adhesive filled with $0.2 \%$ modified nano-clay with poly acrylic acid.

Subgroup 5: Adper single bond was applied according to the manufacturer instructions after using of $35 \%$ phosphoric acid etchant gel.

Cavities were filled incrementally using Filtek Z250 (3M, USA) resin composite in three increments. The first increment was placed incisoaxially, the second axiogingivally and finally the third increment filled all the remained cavity space. Every layer was cured for 40 seconds and then the samples were stored in distilled water for 24 hours before finishing, using finishing burs (D\&Z Lot050606 Germany) and polishing with Soflex discs.

\section{Measurement of Microleakage}

The samples of the first group were incubated for six months at $37^{\circ} \mathrm{C}$ and the second group samples only for 24 hours. Then all the samples were subjected to 1000 thermocycle shocks between 5 and $55^{\circ} \mathrm{C}$ and 30 seconds dwell time, and then processed for microleakage evaluation. After thermal cycles, apexes of the teeth were sealed using sticky wax and teeth surfaces by two coats of nail varnish near to 1 $\mathrm{mm}$ of margins. The samples of each group were immersed in $50 \%$ silver nitrate and then rinsed for 2 minutes under running water and exposed to developing solution under fluorescent light. Then samples were rinsed for 2 minutes and mounted in a self curing acryl and sectioned longitudinally in the middle of restorations and evaluated blindly by two examiners for microleakage using stereomicroscope (MGC-10 N9116234) with 32X magnification and scored in occlusal margins as follows:

$0=$ no leakage was seen.

$1=$ dye penetration into one half of enamel thickness.

$2=$ penetration of dye into all the enamel thickness and DEJ.

$3=$ dye penetration along all the cavity depth.

$4=$ penetration of dye along all cavity depth and toward the dental pulp.

In cervical margins leakage was scored as follows:

$0=$ no leakage was seen.

$1=$ dye penetration into one third of dentin thickness.

$2=$ dye penetration into the two third of dentin thickness.

$4=$ dye penetration along all the cavity wall and toward the dental pulp.

\section{Measurement of Degree of Conversion}

A droplet of the adhesives was placed on a polyethylene film. The solvent of adhesive was gently evaporated for 30 seconds applying a low-pressure air stream and a second film was placed on it to form a very thin layer. The sandwich was placed into the FTIR spectrometer's sample holder and the FTIR absorbance peaks were collected. The samples were then light-cured for 20 s using the same light source and the spectrum was collected for the cured samples. The degree-of-conversion (DC\%) was calculated from the ratio of absorbance intensities of aliphatic $\mathrm{C}=\mathrm{C}\left(\right.$ peak at $\left.1638 \mathrm{~cm}^{-1}\right)$ against internal reference of aromatic C...C (peak at 1608 $\mathrm{cm}^{-1}$ ) before and after curing of the adhesive as follows:

$D C \%=\left(1-\frac{\left(1638 \mathrm{~cm}^{-1} / 1608 \mathrm{~cm}^{-1}\right) \text { peak are after curing }}{\left(1638 \mathrm{~cm}^{-1} / 1608 \mathrm{~cm}^{-1}\right) \text { peak area before curing }}\right) \times 100$

\section{Statistical Analysis}

The data were analyzed using SPSS version 11.5 software and Kruskal - Wallis, Mann-Whitney and Wilcoxon 


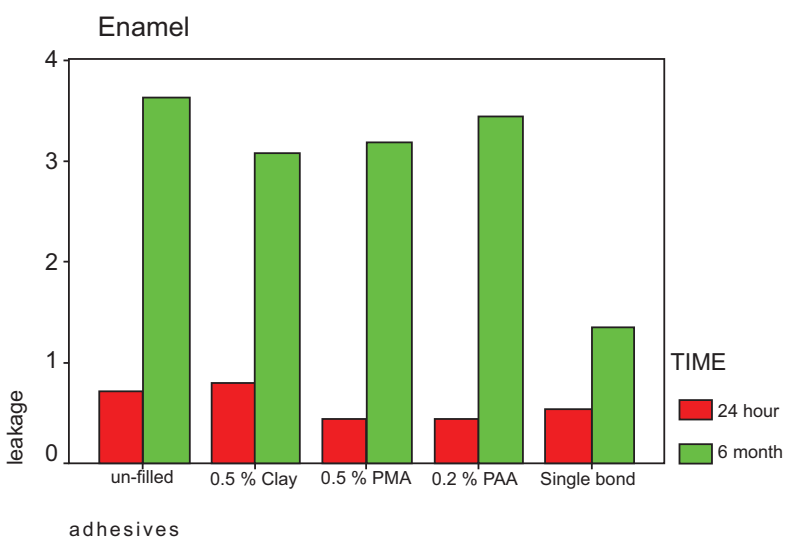

Fig. (1). Leakage in enamel after 24 hours and 6 months storage.

Signed Ranks tests. Materials used in this study are shown in Table 1.

\section{RESULTS}

Mean leakage of the tested adhesives in samples incubated for 24 hours in enamel and dentinal margins are shown in Table $\mathbf{2}$ and Fig. (1). Table $\mathbf{2}$ also shows the degree of conversion of the adhesive. Mean leakage of the tested adhesives in samples incubated for 6 months in enamel and dentinal margins are shown in Table 3 and Fig. (2).

Kruskal-Wallis test showed significant differences between two groups. Mann-Whitney test revealed there was no significant difference in occlusal(enamel) leakage between groups incubated for 24 hours. Significant differences were seen in occlusal(enamel) leakage between those groups incubated for six months and also in gingival margins in samples incubated for 24 hours or six months.

Wilcoxon Signed Ranks test showed that the occlusal(enamel) leakage rank of the tested adhesives stored for 24 hours was significantly lower than dentinal leakage, but after 6 months this difference was only significant in single bond and those adhesive contained fillers modified with PMA.P $<0.05$.

\section{DISCUSSION}

Complexity of the oral cavity from chemical standpoint can endanger adhesive bond durability. Bond strength after the passage of time will decrease [26].
Chemical destruction is occurred following penetration of water into the hybrid and adhesive layer. Hydrophilicity of modern adhesives systems has increased and is a reason to have more water penetration, hydrolysis and softening of the resin and the collagenous network which is not completely covered with resin.



Fig. (2). Leakage in dentin after 24 hours and 6 months storage.

Usually after 3 months of water storage, all adhesives represent somewhat destruction. The water or ethanol base three-step etch and rinse adhesives regarding to terms of bond durability are known as standard adhesives. Following any simplification in application steps of adhesive, bond durability will decrease and only two-step self-etch adhesives remained close to this standard adhesives [2].

Bond to dentin is less stable than bond to enamel. In addition, the difference in thermal expansion between the dentin and restorative materials is more than that of enamel and restorative materials, especially after thermocycling dentinal margins show larger microleakage [27].

In the present study after a 6-month storage, the experimental adhesives in enamel and dentin showed higher microleakage comparing to Adper Single Bond that can be attributed to the amount of HEMA in the recipe of the adhesives. HEMA percent in Adper Single Bond ${ }^{\circledR}$ is between $10 \%$ to $20 \%$. HEMA is widely used in dental adhesives in order to improve wettability of the adhesive and its better penetration into the demineralized dentin. Although the incorporation of HEMA as a hydrophilic co-monomer into the dentin bonding agents improves wetting ability of the adhe-

Table 3. Degree of Marginal Leakage after 6 Months Storage

\begin{tabular}{|c|c|c|}
\hline Adhesive & $\begin{array}{c}\text { Mean Leakage } \\
\text { in Dentin (SD) }\end{array}$ & $\begin{array}{c}\text { Mean Leakage } \\
\text { in Enamel (SD) }\end{array}$ \\
\hline \hline Un- filled & $3.64(1.20)$ \\
\hline $0.5 \%$ clay & $3.36(1.43)$ & $3.09(1.30)$ \\
\hline $0.5 \%$ PMAA-g-clay & $4.00(0.55)$ \\
\hline $0.2 \%$ PAA-g-clay & $3.73(1.9)$ \\
\hline Single Bond & $3.45(1.03)$ & $2.73(1.42)$ \\
\hline
\end{tabular}

SD:Standard Deviation.

PMAA-g-clay: poly(methacrylic acid) grafted clay

PAA-g-clay: poly(acrylic acid) grafted clay 
sives, it provides hydrophilic sites in the structure of the polymerized adhesive. The presence of hydroxyl groups in the chemical structure of the adhesive network increase the water sorption of the adhesive layer which in long term may deteriorate the mechanical properties of the layer and a dramatic drop in the bond strength to the tooth structure. The increased water absorption may also result in swelling and discoloration of the adhesive [28]. It has been mentioned that the higher water absorption in hybrid layer, due to the presence of HEMA, could enhance the hydrolytic destruction of the layer [29]. Incorporation of the low molecular weight HEMA reduces adhesive viscosity which in inadequate application of the bonding system may result in a thin layer with reduced physical and mechanical strength [28].

HEMA is a monofuctional monomer and its polymerization rate is lower compared to multi-functional monomers. A light exposure time of 600 seconds is necessary to reach adequate homopolymerization of HEMA [30]. Therefore higher concentration of HEMA in the adhesive recipe $(26 \%$ wt, Table 2) might reduce the photopolymerization rate with possible decrease in degree of conversion.

In an experimental self etch adhesive 10\% HEMA concentration increased bond strength, but in higher amount because of low degree of polymerization conversion and formation of droplets decreased it [28]. Torkabadi et al. evaluated the durability of a HEMA free single step adhesive ( $\mathrm{G}$ bond) and a HEMA containing adhesive(Tri-s-bond )after one year storage in water. Results showed significant reduction in bond strength to dentin in HEMA containing group while in HEMA free group despite of decrease in the amount of the bond strength its difference was not significant compared to group with a 24- hour storage [29].

Mine et al. examined bond effectiveness of an experimental HEMA free three-step etch \& rinse adhesive. This adhesive had suitable bond strength to enamel but its bond to dentin was significantly inferior compared to control group [31].

High rate of microleakage of test adhesives in the present study can be attributed to high concentration of HEMA $(30 \%)$ in the composition of the adhesives. Ben-Amar studied microleakage of different adhesives. After 21- day storage of the samples in water, the average degree of microleakage in enamel for Single Bond was 0.250 and in dentin 1.20 but the average degree of microleakage in the present study in enamel for Single Bond after 24 hours was found about 0.55 . This difference in microleakage might be related to applied different methods including occlusal forces, different thermal cycles and storage in that research [1].

In a study conducted by Sadek 24 -hour and 3 -month storages had no effect on microleakage of Singe Bond to dentin, while in our research the difference in microleakage after 24 hours and six months was significant and this can be due to different dimensions and cavity form and also storage time in the present study [22].

Filler level optimization of adhesive to achieve maximum bond strength is essential but size and filler shape, hydrophilicity, continuous phase and kind of solvent affect it [14].
Kim showed that the microtensile bond strength appeared to increase when up to $1.0 \%$ wt of the nanofillers were added but higher amounts aggregate easily into large clusters and would decrease the MTBS [15]. The selected percentage of the fillers selected in this research was based on Atai et al. [30] and Kim JS studies results [15] to preclude negative effects of filler percent on adhesive properties.

There is no possible correlation between microleakage and bond strength because leakage occurs in the porous layer located between adhesive and hybrid layer. Therefore placed restorative materials with high bond strength necessarily have no lower microleakage [32, 33].

Similar results were also reported by Pongprueksa who concluded that application of filled adhesive had no effect on microleakage of enamel and dentin while they were effective on dentin bond strength [5].

Therefore, the experimental adhesives that showed comparable bond strength compared to Adper Single Bond, after a long-term storage of the samples in water and subjecting to thermocycle shocks lacked ability to show a good seal.

\section{CONCLUSION}

Although it has been shown that the incorporation of nano-particles into the dental adhesive may improve their mechanical properties and bond strength, the long term effectiveness of the newly developed materials needs more investigation. The results of this study showed that although the incorporation of modified nano-clay particles reduced the short term enamel microleakage of the unfilled experimental adhesive, no improvement was observed in the microleakage in dentin in both short ( 24 hrs) and long times (6 months). The high microleakage in the adhesives is probably attributed to the high concentration of HEMA in the recipe of the bonding agent.

\section{ACKNOWLEDGMENT}

This project financially supported by the research deputy of Isfahan University of Medical Sciences and technically by Torabinejad research centre and Iran Polymer and Petrochemical Institute.

\section{REFERENCES}

[1] Ben Amar A, shapinko E. A microleakage study of single bottle adhesives applied to enamel and cementum and aged by both occlusal loading and thermocycling. Quintessence Int 2005; 36: 17782 .

[2] Summit JB, Robbins JW, Hilton TJ, Schwartz RS, Santos JD, Jr. Fundamentals of operative dentistry. $3^{\text {rd }}$ ed Hanover Park, Quintessence 2006; pp. 183-260.

[3] Boghosian A. Clinical evaluation of a filled adhesive system in class 5 restorations. Compend Contin Educ Dent 1996; 17: 750-2.

[4] Harada TS, Pazinatto FB, Wang L, Atta MT. Effect of number coats of simplified adhesive systems on microleakage of dentin bordered composite restorative. J Contemp Dent Pract 2006; 7: 3441.

[5] Pongprueksa P, Kuphasuk W, Senawongse P. Effect of elastic cavity wall and occlusal loading on microleakage and dentin Bond strength. Oper Dent 2007; 32: 466-75.

[6] Carrilho MR, Carvalho RM, Tay FR, Pashley DH. Effect of storage media on mechanical properties of adhesive systems. Am J Dent 2004; 17: 104-8.

[7] De Munk J, Van Landuyt K, Pumans M. A critical review of the durability of adhesion to tooth tissue: methods and results. J Dent Res 2005; 84: 118-32. 
[8] Armstrong SR, Keller JC, Boyer DB. The influence of water storage and $\mathrm{C}$ - factor on the dentin- resin composite microtensile bond strength and debond pathway utilizing a filled and unfilled adhesive resin. Dent Mater 2001; 17: 268-76.

[9] Van Meerbeek B, Peumance M, Verschueren M. Clinical status of ten dentin adhesive systems. J Dent Res 1994; 73: 1690-702.

[10] Van Meerbeek B, Peumance M, Gladys S, Braem M, lambrechts P, Vanherle G. Three-year clinical effectiveness of four total-etch dentinal adhesive systems in cervical lesions. Quintessence Int 1996; $27: 775-84$

[11] Opdam NJ, Loomancs BA, Roeters FJ, Bronkhorst EM. Five year clinical performance of posterior resin composite restorations place by dental student. J Dent 2004: 32: 379-83.

[12] Nunes MF, Swift EJJR, Perdiago J. Effect of adhesive composition on microtensile bond strength to human dentin. Am J Dent 2001; 14: 340-3.

[13] Montes MA, de Goes MF, da Cunha MR, SoaresAB. A morphological and tensile bond strength evaluation of unfilled adhesive with low viscosity composites and a filled adhesive in one and two coats. J Dent 2001; 29: 435-41.

[14] Miazaki M, Ando S, Hinoura K, Onose H, Moore BK. Influence of filler addition to bonding agent to shear bond strength to bovin dentin. Dent Mater 1995; 11: 234-8.

[15] Kim JS, Cho BH, Lee IB, et al. Effect of the hydrophilic nanofiller loading on the mechanical properties and the microtensile bond strength of an ethanol-based one-bottle dentin adhesive. J Biomed Mater Res B Appl Biomater 2005: 72: 284-91.

[16] Lee JH, Um CM, Lee IB. Rheological properties of resin composites according to variation in monomer and filler composition. Dent Mater 2006; 22: 515-26.

[17] Ellakwa A, Cho N, Lee IB. The effect of resin matrix composition on the polymerization shrinkage and rheological properties of experimental dental composite. Dent Mater 2007; 23: 1229-35.

[18] Chivrac F, Gueguen O, Pollet E, Ahzi S, Makradi A, Averous L. Micromechanical modeling and characterization of the effective properties in starch-based nano-biocomposites. Acta Biomater 2008; 4: 1707-14.

[19] Atai M, Solhi L, Nodehi A, Mirabedini SM, Kasraei S, Akbari K. PMMA-grafted nanoclay as novel filler for dental adhesives. Dent Mater 2009: 25: 339-47.
[20] Conde MC, Zanchi CH, Rodrigues-Junior SA, Carreño NL, Ogliari FA, Piva E. Nanofiller loading level: Influence on selected properties of an adhesive resin. J Dent 2009; 37: 331-5.

[21] Dowling AH, Stamboulis A, Fleming GJ. The influence of montmorillonite clay reinforcement on the performance of a glass ionomer restorative. J Dent 2006; 34: 802-10.

[22] Sadek FT, Moura SK, Ballester RY, Muench A, Cardoso PE. The effecte of long term storage on the microleakage on composite resin restoration qualitative and quantitative evaluation. Pesqui odontol Bras 2003; 17: 261-6.

[23] Gwinnet AJ, YU S. Effect of long-term water storage on dentin bonding. Am J Dent 1995; 8: 109-11.

[24] Crim GA. Microleakage of three dentinal bonding systems: a 6month evaluation. Quintessence Int 1991: 22: 387-9.

[25] Crim GA. Effect of aging on microleakage of restorative system. Am J Dent 1993; 6: 192-4

[26] Hashimoto M, Ohno H, Kaga M, Endo K, Sano H, Oguchi H. In vivo degradation of resin-dentin bond in humans over 1 to 3 years. J Dent Res 2000; 79: 1385-91.

[27] Wahab FK, Shaini FJ, Morgano SM. The effect of thermocycling on microleakage of several commercially available composite Class V restorations in vitro. J Prosthet Dent 2003; 90: 168-74.

[28] Van Landuyt KL, Snauwaert J, Peumans M, De Munck J, Lambrechts P, Van Meerbeek B. The role of HEMA in one-step selfetch adhesives. Dent Mater 2008; 24: 1412-19.

[29] Torkabadi S, Nakajima M, Ikeda M, Foxton RM, Tagami J. Bonding durability of HEMA-free and HEMA-containing one-step adhesives to dentine surrounded by bonded enamel. J Dent 2008; 36: $80-6$.

[30] Atai M, Watts DC, Atai Z. Shrinkage strain-rates of dental resinmonomer and composite systems. Biomaterials 2005; 26: 5015-20.

[31] Mine A, De Munk J, Van Landuyt KL, Poitevin A, Kuboki T, Yoshida. Bonding effectiveness and interfacial characterization of a HEMA/TEGDMA-free three-step etch \& rinse adhesive. J Dent 2008; 36: 767-73.

[32] Ateyah NZ, Elhejazi AA. Shear Bond strength and microleakage of four types of dentin adhesive materials. J Contemp Dent Pract 2004; 5: 63-73.

[33] Costa Pfeifer CS, Braga RR, Cardoso PE. Influence of cavity dimensions, insertion technique and adhesive system on microleakage of class V restorations. J Am Dent Assoc 2006; 137: 197-202.

(C) Mousavinasab et al.; Licensee Bentham Open.

This is an open access article licensed under the terms of the Creative Commons Attribution Non-Commercial License (http://creativecommons.org/licenses/by-nc/3.0/) which permits unrestricted, non-commercial use, distribution and reproduction in any medium, provided the work is properly cited. 